\title{
Light/dark phase-dependent spontaneous activity is maintained in dopamine- deficient mice
}

\author{
Masayo Fujita', Yoko Hagino', Taishi Takeda', Shinya Kasai', Miho Tanaka', Yukio Takamatsu², \\ Kazuto Kobayashi ${ }^{3}$ and Kazutaka Ikeda ${ }^{1 *}$
}

\begin{abstract}
Dopamine is important for motor control and involved in the regulation of circadian rhythm. We previously found that dopamine-deficient (DD) mice became hyperactive in a novel environment $72 \mathrm{~h}$ after the last injection of L3,4-dihydroxyphenylalanine (L-DOPA) when dopamine was almost completely depleted. DD mice did not initially exhibit hyperactivity in their home cages, but the animals exhibited hyperactivity several hours after the last LDOPA injection. The regulation of motor activity in a novel environment and in home cages may be different. A previous study reported that DD mice became active again approximately $24 \mathrm{~h}$ after the last L-DOPA injection. One speculation was that light/dark phase-dependent spontaneous activity might be maintained despite dopamine deficiency. The present study investigated whether spontaneous home cage activity is maintained in DD mice 24$43 \mathrm{~h}$ and $72-91 \mathrm{~h}$ after the last L-DOPA injection. Spontaneous activity was almost completely suppressed during the light phase of the light/dark cycle in DD mice 24 and $72 \mathrm{~h}$ after the last L-DOPA injection. After the dark phase began, DD mice became active 24 and $72 \mathrm{~h}$ after the last L-DOPA injection. DD mice exhibited a similar amount of locomotor activity as wildtype mice $24 \mathrm{~h}$ after the last L-DOPA injection. Although DD mice presented a decrease in activity $72 \mathrm{~h}$ after the last L-DOPA injection, they maintained dark phase-stimulated locomotor activation. Despite low levels of dopamine in DD mice, they exhibited feeding behavior that was similar to wildtype mice. Although grooming and rearing behavior significantly decreased, DD mice retained their ability to perform these activities. Haloperidol treatment significantly suppressed all of these behaviors in wildtype mice but not in DD mice. These results indicate that DD mice maintain some aspects of light/dark phase-dependent spontaneous activity despite dopamine depletion, suggesting that compensatory dopamine-independent mechanisms might play a role in the DD mouse phenotype.
\end{abstract}

Keywords: Dopamine, Dopamine-deficient mice, Light/dark phase, Spontaneous activity

\section{Introduction}

Dopamine is a neurotransmitter that plays important roles in various behaviors, including motor movement, motivation, reward, and cognition [1-3]. Dopamine is also involved in the regulation of circadian rhythm [4]. The functions of dopamine are exerted by its release from dopaminergic neurons in the central nervous system.

\footnotetext{
* Correspondence: ikeda-kz@igakuken.or.jp

${ }^{1}$ Addictive Substance Project, Tokyo Metropolitan Institute of Medical

Science, 2-1-6 Kamikitazawa, Setagaya-ku, Tokyo 156-8506, Japan

Full list of author information is available at the end of the article
}

The dopaminergic pathway in the basal ganglia is considered essential for motor movement. In Parkinson's disease patients, a reduction of dopamine concentrations in the striatum that is caused by the degeneration of dopaminergic neurons in the substantia nigra pars compacta leads to motor impairment [5]. The removal of dopaminergic neurons by neurotoxin application leads to motor impairment $[6,7]$. The blockade of dopaminergic neurotransmission with dopamine receptor antagonists also results in motor impairment [8]. In contrast, dopamine transporter knockout mice, which have high levels of dopamine, exhibit hyperactivity [9]. Based on

(c) The Author(s). 2017 Open Access This article is distributed under the terms of the Creative Commons Attribution 4.0 International License (http://creativecommons.org/licenses/by/4.0/), which permits unrestricted use, distribution, and reproduction in any medium, provided you give appropriate credit to the original author(s) and the source, provide a link to the Creative Commons license, and indicate if changes were made. The Creative Commons Public Domain Dedication waiver (http://creativecommons.org/publicdomain/zero/1.0/) applies to the data made available in this article, unless otherwise stated. 
these observations, dopamine concentrations may be correlated with the extent of locomotor activity.

The role of dopamine in motor function was investigated using a dopamine-deficient (DD) mouse model $[10,11]$. DD mice are genetically manipulated to not produce dopamine. They lack the tyrosine hydroxylase $(\mathrm{TH})$ gene, but $\mathrm{TH}$ expression is rescued in noradrenergic neurons to prevent disruptions of norepinephrine and epinephrine. DD mice die within 30 days after birth because of starvation [12]. However, they can live, grow normally, and become adults when they receive daily injections of L-3,4-dihydroxyphenylalanine (L-DOPA), a precursor of dopamine, beginning at 2 weeks of age.

Unexpectedly, we previously found that DD mice became hyperactive in a novel environment $72 \mathrm{~h}$ after the last L-DOPA injection, when extracellular dopamine concentrations in the brain were almost completely depleted [13]. In contrast, $24 \mathrm{~h}$ after the last L-DOPA injection, when extracellular dopamine concentrations in the brain were low, DD mice did not become hyperactive. These observations indicate that dopamine concentrations are not always correlated with the extent of locomotor activity, and a dopamine-independent motor control system may be involved in hyperactivity in a novel environment.

DD mice did not initially exhibit hyperactivity in their home cage, but they later exhibited hyperactivity $\sim 10 \mathrm{~h}$ after the last L-DOPA injection and then became hypoactive thereafter [12]. Our previous study also showed that DD mice were hypoactive in their home cage but not in a novel environment $72 \mathrm{~h}$ after the last L-DOPA injection [13]. However, DD mice became active again $\sim 24 \mathrm{~h}$ after the last L-DOPA injection [14]. The mechanisms that were associated with the second wave of activity were unclear but might be attributable to the maintenance of light/dark phase-dependent spontaneous activity despite dopamine insufficiency.

In the present study, we focused on the association between the $12 \mathrm{~h} / 12 \mathrm{~h}$ light/dark cycle and home cage activity in DD mice. We examined home cage activity in DD mice 24-43 $\mathrm{h}$ and 72-91 $\mathrm{h}$ after the last L-DOPA injection and examined spontaneous behaviors. Although DD mice were hypoactive during the light phase of the light/ dark cycle, they became active when the dark phase began (i.e., the active phase in mice). Dopamine receptor blockade did not significantly inhibit spontaneous behavior in DD mice in the dark phase, suggesting that dopamineindependent mechanisms may play a compensatory role in maintaining circadian rhythm-regulated spontaneous activity that is controlled by the light/dark cycle.

\section{Methods}

Mice

DD mice were created as described previously [11]. We used wildtype and DD mouse littermates from crosses of heterozygous/heterozygous DD mice on a C57BL/6 J genetic background. The experimental procedures and housing conditions were approved by the Institutional Animal Care and Use Committee (Animal Experimentation Ethics Committee of Tokyo Metropolitan Institute of Medical Science; approval no. 12-43). All of the animals were cared for and treated humanely in accordance with our institutional animal experimentation guidelines. All of the mice were housed in an animal facility that was maintained at $23^{\circ} \mathrm{C} \pm 1{ }^{\circ} \mathrm{C}$ and $55 \% \pm 5 \%$ relative humidity under a $12 \mathrm{~h} / 12 \mathrm{~h}$ light/dark cycle (lights on at 8:00 AM, lights off at 8:00 PM). Food and water were available ad libitum. For routine maintenance of the DD mice, $50 \mathrm{mg} / \mathrm{kg}$ L-DOPA (Sigma Aldrich, St. Louis, MO, USA) dissolved in $2.5 \mathrm{mg} / \mathrm{ml}$ ascorbic acid (Sigma Aldrich, St. Louis, MO, USA) solution in saline was intraperitoneally (i.p.) administered six times per week. DD mice were given paste-type food or DietGel (Clear $\mathrm{H} 2 \mathrm{O}$, Westbrook, ME, USA), in addition to usual food pellets. We examined both male and female 10-30 week old mice.

\section{Locomotor activity assessment}

Locomotor activity was measured with a Supermex apparatus (Muromachi Kikai, Tokyo, Japan) and a sensor monitor that was mounted above the chamber. All locomotor activity counts were automatically summed and recorded every $10 \mathrm{~min}$. DD mice received their last LDOPA $(50 \mathrm{mg} / \mathrm{kg}$ ) injection at 2:00 PM the day before the test or 3 days before the test. Each mouse was housed in its home cage on the Supermex apparatus $3 \mathrm{~h}$ before the locomotor activity test (24 or $72 \mathrm{~h}$ after the last L-DOPA injection) to habituate them to the environment. The locomotor activity test was performed from 5:00 PM to 9:00 AM, 27-43 h or 75-91 h after the last L-DOPA injection. To analyze the effect of haloperidol treatment, the mice received their last L-DOPA injection at 2:00 PM the day before the test and were subcutaneously injected with $1 \mathrm{mg} / \mathrm{kg}$ haloperidol (Sigma Aldrich, St. Louis, MO, USA) dissolved in $0.08 \%$ lactic acid (Wako Pure Chemical Industries, Osaka, Japan) at 5:00 PM (i.e., immediately before the locomotor activity test).

\section{Spontaneous activity assessment}

Spontaneous home cage behavior was recorded with a video camera. During recording, DietGel was used for feeding. For mice that did not receive a haloperidol injection, we evaluated the video that was recorded during the first $6 \mathrm{~h}$ of the dark phase (8:00 PM to 2:00 AM). For mice that received a haloperidol injection, we evaluated the video that was recorded during the first $3 \mathrm{~h}$ of the dark phase (8:00 PM to 11:00 PM). We analyzed the following spontaneous behaviors: eating, grooming, and 
rearing. Eating behavior was defined as the mouse placing its mouth in contact with the DietGel. For eating and grooming behavior, the number of bouts and duration were recorded. If the interval between two bouts was $>5 \mathrm{~s}$, then they were counted as separate bouts. Rearing behavior was defined as the mouse standing on its hind legs. For rearing behavior, only the number of bouts was counted. Patterns of grooming behavior during the first $2 \mathrm{~h}$ of the dark phase were analyzed according to a previous report [15] with some modifications. The number of grooming bouts for each of five anatomical areas (i.e., forepaws, nose/face, head, body, hind legs/tail/genitals) was counted. The percentage of the number of bouts for each anatomical area relative to the total number of grooming bouts was calculated.

\section{Statistical analysis}

The time course data are presented as mean \pm SE. The other data are shown as box plots. For multiple comparisons, the data were analyzed using the Kruskal-Wallis test. To perform a comparison of each pair, the data were analyzed using the Steel-Dwass test. For comparisons between two groups, the data were analyzed using the Mann-Whitney two-tailed U-test.Values of $p<0.05$ were considered statistically significant. The data were analyzed using BellCurve for Excel software (Social Survey Research Information, Tokyo, Japan).

\section{Results}

Locomotor activity in the home cage increased in both wildtype mice and DD mice during the dark phase

We first examined locomotor activity in the home cage in wildtype mice and DD mice. DD mice were hypoactive during the light phase (5:00 PM to 8:00 PM) 24 and $72 \mathrm{~h}$ after the last L-DOPA injection. DD mice $24 \mathrm{~h}$ after the last L-DOPA injection became active immediately after beginning the dark phase and remained active during the dark phase (Fig. 1). Activity in DD mice $24 \mathrm{~h}$ after the last L-DOPA injection was not significantly different from wildtype mice. The time course of locomotor activity was similar to wildtype mice, indicating that activity in DD mice was associated with the light/ dark cycle. DD mice $72 \mathrm{~h}$ after the last L-DOPA injection also became active after the beginning of the dark phase while the extent of locomotor activity was less than wildtype and DD mice $24 \mathrm{~h}$ after the last L-DOPA injection (Fig. 1), indicating that the dark phasedependent increase in locomotor activity remained even with extremely low dopamine levels.

\section{Eating behavior was normal but food intake significantly decreased in DD mice}

Activity was higher during the first half of the dark phase in wildtype mice and DD mice $24 \mathrm{~h}$ after the last L-DOPA injection. We next investigated spontaneous behavior in DD mice by recording activity in the first $6 \mathrm{~h}$ of the dark phase. We first analyzed eating behavior. The number of feeding bouts in the first hour was high and then gradually decreased in wildtype and DD mice (Fig. 2a), although no significant difference was observed between wildtype and DD mice. The total number of feeding bouts in the first $6 \mathrm{~h}$ of the dark phase was higher in DD mice $24 \mathrm{~h}$ after the last L-DOPA injection compared with DD mice $72 \mathrm{~h}$ after the last L-DOPA injection, with no significant difference between wildtype and DD mice (Fig. 2b). The duration of eating behavior was not significantly different between wildtype and DD mice (Fig. 2c, d). These results indicate that DD mice, even $72 \mathrm{~h}$ after the last L-DOPA injection, did not lose their motivation to eat. We next investigated whether DD mice actually ate their food. We used DietGel because DD mice have difficulty eating hard food pellets.

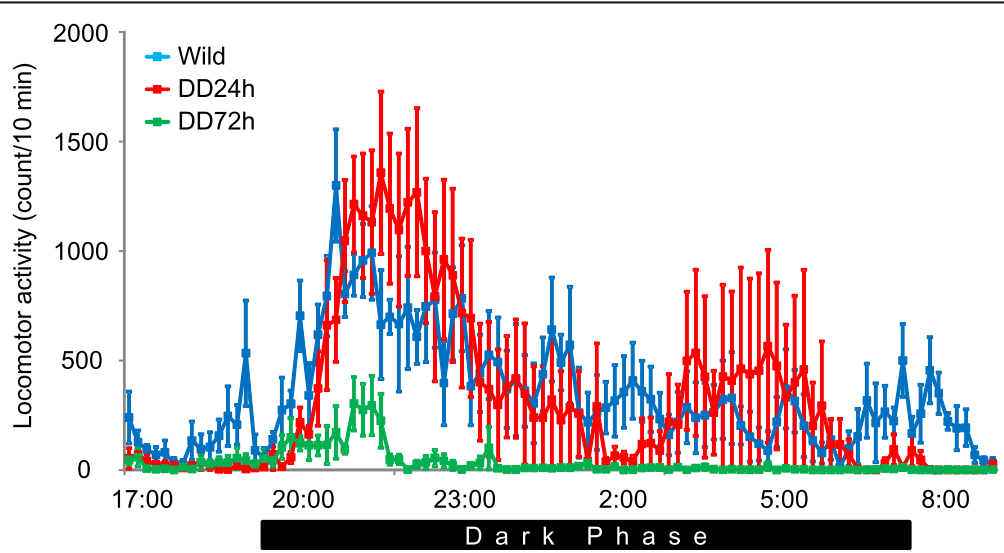

Fig. 1 Locomotor activity in the home cage in wildtype mice and DD mice $24 \mathrm{~h}$ (DD24h) and $72 \mathrm{~h}$ (DD72h) after the last L-DOPA injection ( $n=6$ per group). The dark phase was from 8:00 PM to 8:00 AM. The data are expressed as mean \pm SEM 

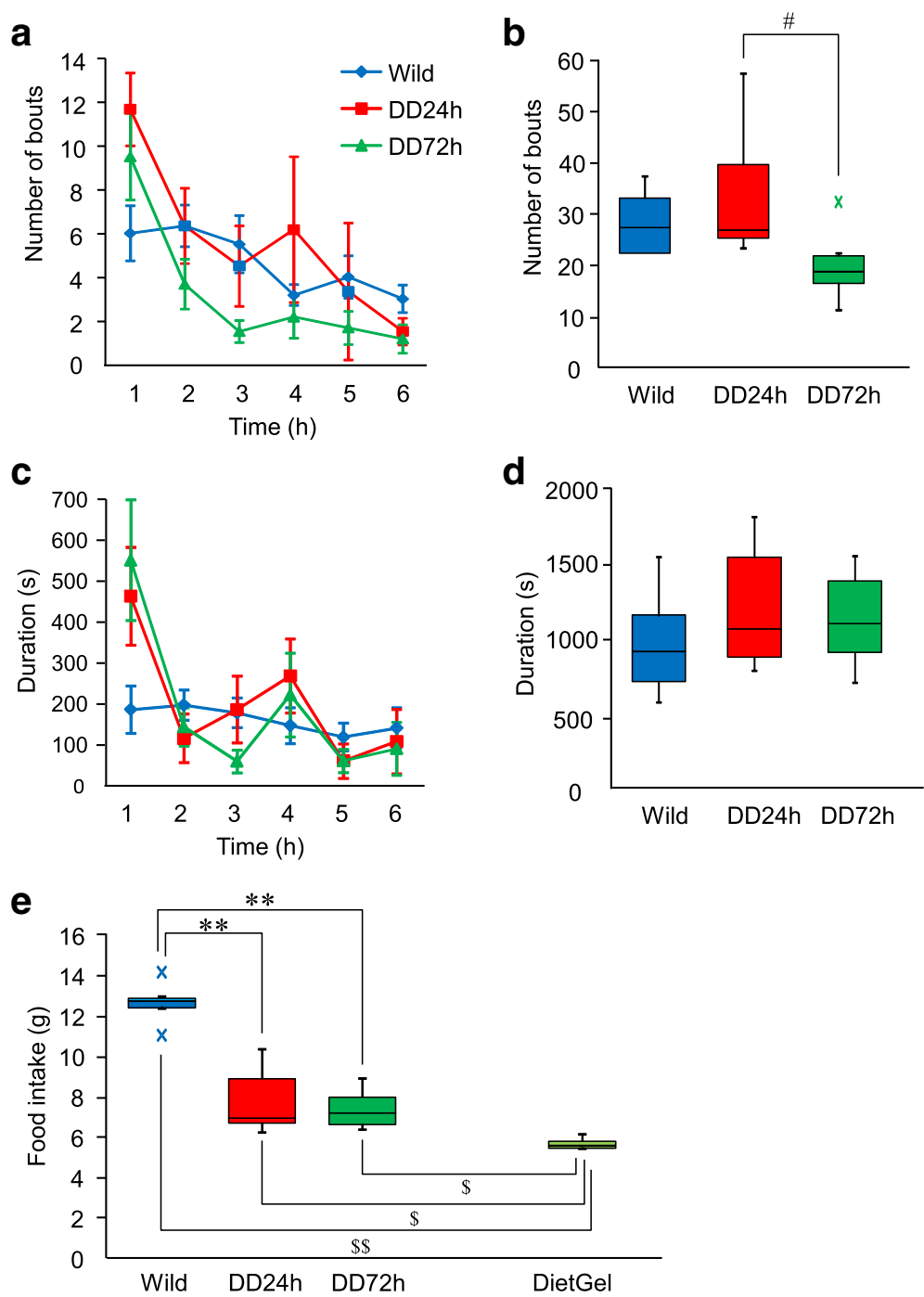

Fig. 2 Eating behavior. a Time course analysis of frequency of eating during the first $6 \mathrm{~h}$ of the dark phase. The data are expressed as mean \pm SEM. $\mathbf{b}$ Box plot showing total number of eating bouts during the first $6 \mathrm{~h}$ of the dark phase. ${ }^{*} p<0.05$, compared with DD mice $24 \mathrm{~h}$ after the last L-DOPA injection. c Time course analysis of the duration of eating during the first $6 \mathrm{~h}$ of the dark phase. The data are expressed as mean \pm SEM. $\mathbf{d}$ Box plot showing total duration of eating during the first $6 \mathrm{~h}$ of the dark phase. e Box plot showing food intake and amount of water evaporation from DietGel from 2:00 PM to 9:00 AM. ${ }^{* *} p<0.01$, compared with wildtype mice; ${ }^{\$} p<0.05$, $\$ \$ p<0.01$, compared with DietGel

Approximately $5 \mathrm{~g}$ of water evaporated from the DietGel (Fig. 2e). After taking into account water evaporation, the amount of DietGel significantly decreased in DD mice both 24 and $72 \mathrm{~h}$ after the last L-DOPA injection (Fig. 2e), indicating that DD mice ate it. However, total food intake was significantly lower in DD mice than in wildtype mice (Fig. 2e). DD mice lost more than $1 \mathrm{~g}$ of their body weight if L-DOPA injections were skipped for 1 day. These results indicate that DD mice ate their feed although they exhibited dopamine depletion, but their food intake was less compared with wildtype mice.
Grooming behavior decreased and patterns of grooming behavior were altered in DD mice

We next investigated grooming behavior. We did not observe a significant difference in the time course of the number of grooming bouts between wildtype mice and DD mice $24 \mathrm{~h}$ after the last L-DOPA injection, whereas DD mice $72 \mathrm{~h}$ after the last L-DOPA injection exhibited a significant decrease in the number of grooming bouts in the second, third, and fourth hours of the dark phase (Fig. 3a). The total number of grooming bouts in the first $6 \mathrm{~h}$ of the dark phase significantly decreased in DD mice. DD mice $72 \mathrm{~h}$ after the last L-DOPA injection 

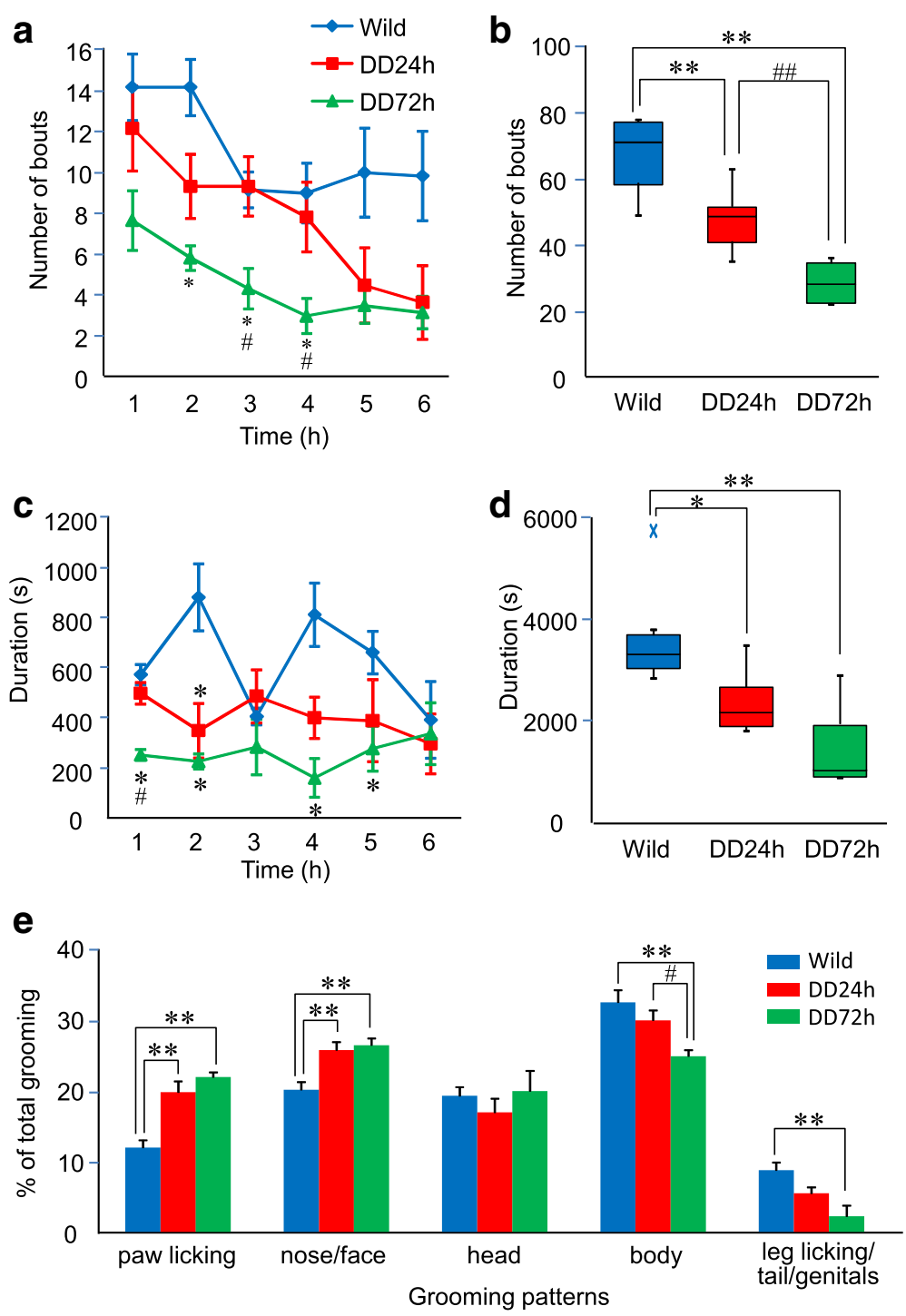

Fig. 3 Grooming behavior. a Time course of frequency of grooming behavior during the first $6 \mathrm{~h}$ of the dark phase. The data are expressed as mean \pm SEM. ${ }^{*} p<0.05$, compared with wildtype mice; ${ }^{*} p<0.05$, compared with DD mice $24 \mathrm{~h}$ after the last L-DOPA injection. $\mathbf{b}$ Box plot showing total number of bouts of grooming during the first $6 \mathrm{~h}$ of the dark phase. ${ }^{* *} p<0.01$, compared with wildtype mice; ${ }^{\# \#} p<0.01$, compared with DD mice $24 \mathrm{~h}$ after the last L-DOPA injection. c Time course of duration of grooming behavior during the first $6 \mathrm{~h}$ of the dark phase. The data are expressed as mean \pm SEM. ${ }^{*} p<0.05$, compared with wildtype mice; ${ }^{*} p<0.05$, compared with DD mice $24 \mathrm{~h}$ after the last L-DOPA injection. $\mathbf{d}$ Box plot showing total duration of grooming during the first $6 \mathrm{~h}$ of the dark phase. ${ }^{*} p<0.05$, ${ }^{* *} p<0.01$, compared with wildtype mice. e Percentage of patterns of grooming behavior relative to total grooming during the first $2 \mathrm{~h}$ of the dark phase. The data are expressed as mean \pm SEM. ${ }^{* *} p<0.01$, compared with wildtype mice; ${ }^{\#} p<0.05$, compared with DD mice $24 \mathrm{~h}$ after the last L-DOPA injection

presented the fewest grooming bouts (Fig. 3b). The duration of grooming behavior was significantly less in DD mice $24 \mathrm{~h}$ after the last L-DOPA injection than in wildtype mice in the second hour of the dark phase. The duration of grooming behavior was significantly less in DD mice $72 \mathrm{~h}$ after the last L-DOPA injection than in wildtype mice in the first, second, fourth, and fifth hours of the dark phase (Fig. 3c). The total duration of grooming behavior in the first $6 \mathrm{~h}$ of the dark phase also significantly decreased in DD mice. DD mice $72 \mathrm{~h}$ after the last L-DOPA injection exhibited the shortest duration of grooming (Fig. 3d). Although the amount of grooming behavior may be correlated with dopamine levels, these results indicate that DD mice, even $72 \mathrm{~h}$ after the last LDOPA injection, engaged in grooming behavior despite having extremely low levels of dopamine.

Patterns of grooming behavior are affected by various stimuli, including stress and gene modification $[15,16]$. We evaluated patterns of grooming behavior in DD mice. DD mice presented more forepaw and nose/face 


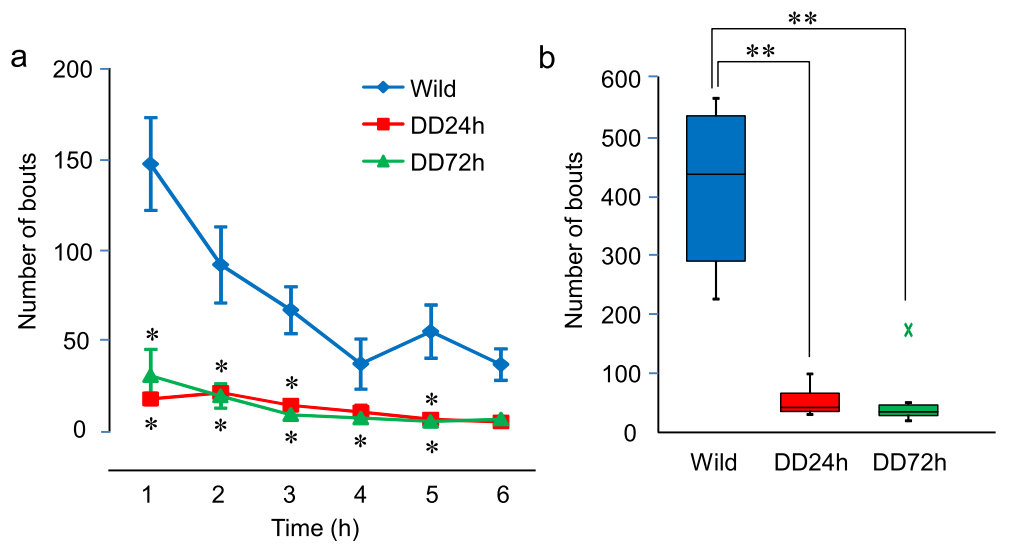

Fig. 4 Rearing behavior. a Time course of frequency of rearing behavior during the first $6 \mathrm{~h}$ of the dark phase. The data are expressed as mean \pm SEM. ${ }^{*} p<0.05$, compared with wildtype mice. $\mathbf{b}$ Box plot showing total number of bouts of rearing during the first $6 \mathrm{~h}$ of the dark phase. ${ }^{* *} p<0.01$, compared with wildtype mice

grooming, accompanied by a decrease in dopamine levels (Fig. 3c), indicating that DD mice spent more time grooming the cranial side of the body than the caudal side.

\section{Rearing behavior significantly decreased in DD mice}

We also investigated the frequency of rearing behavior. Wildtype mice explored the vertical sides of the cage and reared frequently (Fig. $4 a, b)$. DD mice exhibited significantly less rearing behavior 24 and $72 \mathrm{~h}$ after the last L-DOPA injection (Fig. 4a, b). Hanging from the wire top of the cage was seen in all wildtype mice, whereas only one of the six DD mice both 24 and $72 \mathrm{~h}$ after the last L-DOPA injection hung from the wire top of the cage during the first $6 \mathrm{~h}$ of the dark phase.

\section{Increase in locomotor activity during dark phase was} maintained after haloperidol treatment in DD mice To investigate whether the increase in locomotor activity during the dark phase was dopamine-dependent, wildtype mice and DD mice were treated with haloperidol $3 \mathrm{~h}$ before the dark phase began. Locomotor activity in wildtype mice was almost completely inhibited for approximately $6 \mathrm{~h}(\sim 11: 00 \mathrm{PM})$ after haloperidol treatment and then gradually increased, likely because the effect of haloperidol subsided (Fig. 5). In contrast, DD mice exhibited an increase in locomotor activity compared with wildtype mice soon after dark phase began (Fig. 5). Haloperidol treatment decreased locomotor activity compared with no treatment in DD mice (see Fig. 1). After haloperidol treatment, DD mice became mostly inactive after 11:00 PM. These results indicated that increase in locomotor activity during dark phase may be partially dopamineindependent in DD mice.
Eating behavior was maintained after haloperidol treatment in DD mice

The effect of haloperidol lasted until 11:00 PM in wildtype mice. We investigated eating behavior from 8:00 PM to 11:00 PM. Wildtype mice exhibited no eating behavior after haloperidol treatment (Fig. 6a, b). DD mice did not exhibit a significant haloperidol-induced decrease in eating behavior (Fig. 6a, b), indicating that eating behavior in DD mice might be partially regulated by dopamine-independent mechanisms.

Haloperidol significantly decreased grooming and rearing behavior in wildtype mice but not in DD mice

Haloperidol treatment significantly decreased the frequency (Fig. 7a) and duration (Fig. 7b) of grooming behavior in wildtype mice. Haloperidol did not significantly decrease grooming behavior in DD mice (Fig. 7a, b). Haloperidol significantly decreased rearing behavior in

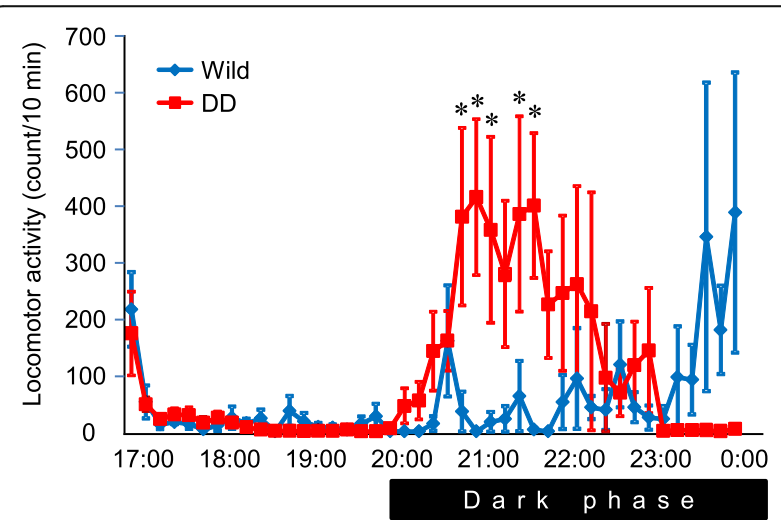

Fig. 5 Effect of haloperidol on locomotor activity. Haloperidol was injected at 5:00 PM. The dark phase began at 8:00 PM. The data are expressed as mean \pm SEM. ${ }^{*} p<0.05$, compared with wildtype mice 


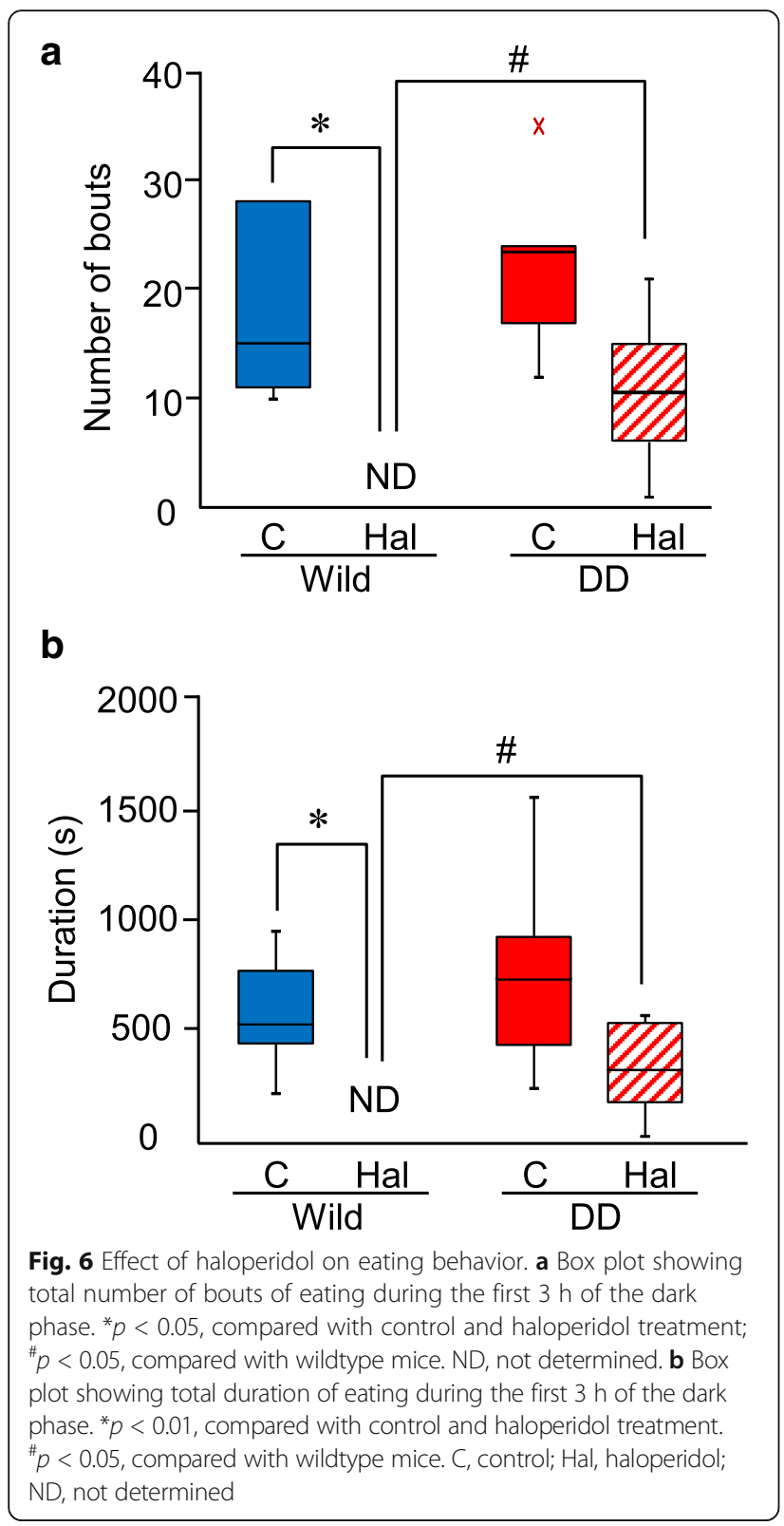

wildtype mice but not in DD mice (Fig. 7c). Thus, DD mice were less sensitive than wildtype mice to the effects of haloperidol treatment on grooming and rearing behavior.

\section{Discussion}

Spontaneous activity in the home cage in DD mice was almost completely suppressed during the light phase of the light/dark cycle, but DD mice became active when the dark phase began. A previous study found that DD mice became active $24 \mathrm{~h}$ after the last L-DOPA injection [14]. In the present study, light/dark phase-dependent spontaneous activity in DD mice was a novel finding. Two possibilities may explain light/dark phase-dependent

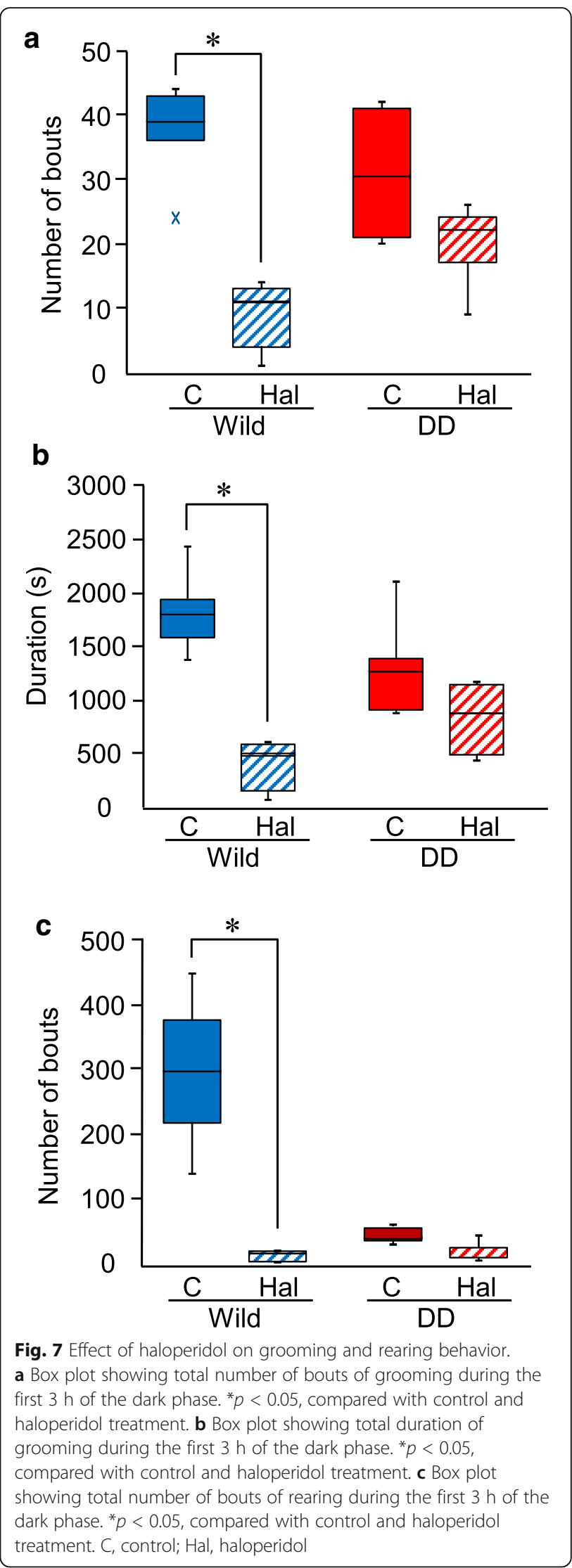


spontaneous activity in DD mice. One possibility is that a blackout stimulus increases locomotor activity. Another possibility is that circadian rhythm may remain intact in DD mice. Dopamine plays a role in modulating circadian rhythm and is involved in regulating gene expression that is related to circadian rhythm, body temperature, and hormone secretion [4]. Dopamine dysfunction in Parkinson's disease patients is associated with disturbances in circadian rhythm $[17,18]$. In a previous study, nonhuman primates were subjected to 1-methyl-4-phenyl-1,2,3,6tetrahydopyridine (MPTP)-induced lesions of dopaminergic neurons. The results showed that visual cues of lightness and darkness were required to maintain circadian rhythm, and continuous light exposure led to the disappearance of circadian rhythm [19]. To clarify whether a blackout stimulus is required to increase spontaneous activity or whether normal circadian rhythm is retained, future studies need to investigate spontaneous activity in DD mice under constant dark or light conditions.

DD mice $24 \mathrm{~h}$ after the last L-DOPA injection exhibited spontaneous activity that was similar to wildtype mice during the dark phase. Although the amount of some aspects of activity significantly decreased, spontaneous activity did not disappear in DD mice even $72 \mathrm{~h}$ after the last L-DOPA injection. A previous study reported that the levels of extracellular dopamine in the striatum in DD mice $24 \mathrm{~h}$ after the last L-DOPA injection were less than $2 \%$ of wildtype mice [13]. Moreover, extracellular dopamine levels in the striatum were below the limit of detection in DD mice $72 \mathrm{~h}$ after the last LDOPA injection [13]. Such a low level of dopamine would be sufficient to lead to severe motor symptoms of Parkinson's disease. A previous study showed that $80 \%$ dopamine depletion resulted in motor symptoms of Parkinson's disease [20]. DD mice may have retained spontaneous locomotor activity because compensatory mechanisms may have been engaged. DD mice have intrinsically low dopamine levels beginning at birth, and such long-term dopamine depletion may trigger the activation of compensatory pathways. Constitutive dopamine $\mathrm{D}_{2}$ receptor knockout mice did not present hypoactivity, but inducible knockout mice presented hypoactivity, indicating that compensatory mechanisms may be engaged in constitutive $D_{2}$ receptor knockout mice [21]. Moreover, acute depletion of dopaminergic neurons by high dose of 6-hydroxydopamine (6-OHDA) treatment caused severe motor impairment whereas gradual depletion of dopaminergic neurons by low dose of 6-OHDA treatment did not [22]. Compensatory dopamine-independent mechanisms may be responsible for spontaneous activity in DD mice.

Spontaneous activity was not significantly suppressed by haloperidol treatment in DD mice, whereas spontaneous activity was significantly inhibited in wildtype mice.
Although haloperidol mainly blocks dopamine $\mathrm{D}_{2}$ receptors, spontaneous activity that likely is regulated by dopamine was blocked by haloperidol treatment in wildtype mice. One possibility is that dopamine-dependent activity was blocked by haloperidol treatment. Therefore, spontaneous activity in DD mice might be partially regulated by dopamine-independent mechanisms. Alternatively, low levels of dopamine might alter the function of dopamine receptors or upregulate dopamine receptors, resulting in lower sensitivity to haloperidol treatment.

Dopamine is involved in regulating feeding behavior [23]. Neurotoxin-induced disruptions of dopaminergic neurons resulted in hypophasia [24], and dopamine receptor blockade induced hypophasia [25]. Excessive dopamine concentrations that are induced by psychostimulant treatment reduced food intake [26]. Moreover, dopamine insufficiency was shown to cause obesity [27]. The mechanisms of dopamine's involvement in feeding behavior have not yet been clearly demonstrated. Previous studies showed that DD mice became hypophasia $10 \mathrm{~h}$ after L-DOPA treatment $[12,14,28]$, indicating that dopamine is essential to maintain sufficient food intake. Hypophasia in DD mice was rescued by the recovery of $\mathrm{TH}$ gene expression in the dorsal striatum [14, 29]. Interestingly, DD mice showed eating behavior when food was served after food deprivation $24 \mathrm{~h}$ after the last L-DOPA injection [14]. The experimental protocol in this previous study [14] was different from the present study. Nonetheless, the results of both studies support the hypothesis that the motivation to eat is maintained even with dopamine insufficiency, but overall food intake decreases. Parkinson's disease patients suffer from dysphagia, and some patients can be treated with dopaminergic stimulation [30, 31]. Moreover, 6-OHDAtreated rats exhibited dysphagia [32]. Dopamine deficiency may decrease the ability to swallow, which would lead to a decrease in food intake in DD mice.

Dopamine is also involved in grooming behavior. The blockade of dopamine transmission by a dopamine receptor antagonist reduced grooming behavior [33]. Both the frequency and duration of grooming behavior significantly decreased in DD mice. The pattern of grooming behavior was also affected in DD mice, in which the proportion of paw licking and nose/face grooming increased while body/leg licking and tail/genital grooming decreased. A previous study reported that dopamine $D_{1}$ agonist treatment increased the grooming of flank regions, whereas $D_{2}$ agonist treatment increased genital grooming compared with control rats [34]. Altogether, these findings suggest that the dopamine might be important for patterns of grooming behavior. Mice that were subjected to the stress of light exposure exhibited an increase in grooming rostral areas [15]. One possibility is that DD mice are more vulnerable and sensitive to 
external stress than wildtype mice. A significant decrease in rearing behavior was observed in DD mice, which is consistent with previous studies [32, 35]. Dopamine levels may be correlated with the extent of vertical movement [22]. In the present study, the significant decrease in rearing behavior was associated with low extracellular dopamine levels in DD mice.

\section{Conclusions}

In conclusion, DD mice maintained similar light/dark phase-dependent spontaneous activity as wildtype mice, suggesting that compensatory mechanisms may be engaged in DD mice. The decrease in the sensitivity to haloperidol treatment indicates that spontaneous activity in DD mice may be partially controlled by dopamineindependent mechanisms.

\section{Abbreviations}

6-OHDA: 6-hydroxydopamine; DD: dopamine deficient; L-DOPA: L-3,4dihydroxyphenylalanine; TH: tyrosine hydroxylase

\section{Acknowledgements}

We thank Michael Arends for assistance with editing the manuscript, Etsuko Kamegaya and Yukiko Matsushima for assistance with breeding the DD mice, and Junko Hasegawa for assistance with DD mouse genotyping.

\section{Funding}

This work was supported by grants from the Ministry of Health, Labour and Welfare of Japan (H22-lyaku-015, H25-lyaku-020, and $17 \mathrm{mk010107} 6$ h0002), JSPS KAKENHI $(24,659,549,24,659,490,24,650,205,25,116,532,15 \mathrm{H} 01303$, 16 K15565, 16H06276), and MEXT KAKENHI (25116532), the Smoking Research Foundation, the Naito Foundation, and the Astellas Foundation for Research on Metabolic Disorders.

\section{Availability of data and materials}

All of the data generated and analyzed in this study are included in the published article.

\section{Authors' contributions}

$\mathrm{MF}$ and $\mathrm{KI}$ conceived and designed the experiments and wrote the paper. $M F, Y H, T$, MT, and $Y T$ performed the behavioral experiments. KK provided the DD mice. All authors read and approved the final manuscript.

\section{Ethics approval and consent to participate}

The experimental procedures and housing conditions were approved by the Institutional Animal Care and Use Committee (Animal Experimentation Ethics Committee of Tokyo Metropolitan Institute of Medical Science; approval no. 12-43).

\section{Consent for publication}

Not applicable.

\section{Competing interests}

The authors declare that they have no competing interests.

\section{Publisher's Note}

Springer Nature remains neutral with regard to jurisdictional claims in published maps and institutional affiliations.

\section{Author details}

${ }^{1}$ Addictive Substance Project, Tokyo Metropolitan Institute of Medical Science, 2-1-6 Kamikitazawa, Setagaya-ku, Tokyo 156-8506, Japan. ${ }^{2}$ Center for Basic Technology Research, Tokyo Metropolitan Institute of Medical Science, 2-1-6 Kamikitazawa, Setagaya-ku, Tokyo 156-8506, Japan. ${ }^{3}$ Department of Molecular Genetics, Institute of Biomedical Sciences, Fukushima Medical University, 1 Hikarigaoka, Fukushima 960-1295, Japan.
Received: 27 July 2017 Accepted: 3 October 2017

Published online: 16 October 2017

\section{References}

1. Haber SN. The place of dopamine in the cortico-basal ganglia circuit. Neuroscience. 2014;282:248-57.

2. Spanagel R, Weiss F. The dopamine hypothesis of reward: past and current status. Trends Neurosci. 1999;22:521-7.

3. Salamone JD, Correa M. The mysterious motivational functions of mesolimbic dopamine. Neuron. 2012;76:470-85.

4. Korshunov KS, Blakemore $\sqcup$, Trombley PQ. Dopamine: a modulator of circadian rhythms in the central nervous system. Front Cell Neurosci. 2017;11:91.

5. Cacabelos R. Parkinson's disease: from pathogenesis to pharmacogenomics. Int J Mol Sci. 2017;18:E551.

6. Sedelis M, Schwarting RK, and Huston JP. Behavioral phenotyping of the MPTP mouse model of Parkinson's disease. Behav Brain Res 2001;125:109-125.

7. Deumens R, Blokland A, Prickaerts J. Modeling Parkinson's disease in rats: an evaluation of 6-OHDA lesions of the nigrostriatal pathway. Exp Neurol. 2002:175:303-17.

8. Holtzman SG, Young CW. Motor activity of squirrel monkeys measured with an ultrasonic motion sensor. Pharmacol Biochem Behav. 1991:38:633-7.

9. Takamatsu Y, Hagino Y, Sato A, Takahashi T, Nagasawa SY, Kubo Y, et al. Improvement of learning and increase in dopamine level in the frontal cortex by methylphenidate in mice lacking dopamine transporter. Curr Mol Med. 2015:15:245-52.

10. Zhou QY, Palmiter RD. Dopamine-deficient mice are severely hypoactive, adipsic, and aphagic. Cell. 1995:83:1197-209.

11. Nishii K, Matsushita N, Sawada H, Sano H, Noda Y, Mamiya T, et al. Motor and learning dysfunction during postnatal development in mice defective in dopamine neuronal transmission. J Neurosci Res. 1998;54:450-64.

12. Palmiter RD. Dopamine signaling in the dorsal striatum is essential for motivated behaviors: lessons from dopamine-deficient mice. Ann N Y Acad Sci. 2008;1129:35-46

13. Hagino $Y$, Kasai S, Fujita M, Setogawa S, Yamaura H, Yanagihara D, et al. Involvement of cholinergic system in hyperactivity in dopamine-deficient mice. Neuropsychopharmacology. 2015:40:1141-50.

14. Szczypka MS, Rainey MA, Kim DS, Alaynick WA, Marck BT, Matsumoto AM, et al. Feeding behavior in dopamine-deficient mice. Proc Natl Acad Sci U S A. 1999;96:12138-43.

15. Kalueff $A V$, Tuohimaa $P$. The grooming analysis algorithm discriminates between different levels of anxiety in rats: potential utility for neurobehavioural stress research. J Neurosci Methods. 2005;143:169-77.

16. Kalueff AV, Stewart AM, Song C, Berridge KC, Graybiel AM, Fentress JC. Neurobiology of rodent self-grooming and its value for translational neuroscience. Nat Rev Neurosci. 2016;17:45-59.

17. Videnovic A, Golombek D. Circadian and sleep disorders in Parkinson's disease. Exp Neurol. 2013:243:45-56.

18. Li S, Wang Y, Wang F, LF H, Liu CFA. New perspective for Parkinson's disease: circadian rhythm. Neurosci Bull. 2017:33:62-72.

19. Fifel K, Vezoli J, Dzahini K, Claustrat B, Leviel V, Kennedy H, et al. Alteration of daily and circadian rhythms following dopamine depletion in MPTP treated non-human primates. PLoS One. 2014;9:e86240.

20. Dauer W, Przedborski S. Parkinson's disease: mechanisms and models. Neuron. 2003;39:889-909.

21. Bello EP, Casas-Cordero R, Galinanes GL, Casey E, Belluscio MA, Rodriguez V, et al. Inducible ablation of dopamine D2 receptors in adult mice impairs locomotion, motor skill learning and leads to severe parkinsonism. Mol Psychiatry. 2017;22:595-604.

22. Willard AM, Bouchard RS, Gittis AH. Differential degradation of motor deficits during gradual dopamine depletion with 6-hydroxydopamine in mice. Neuroscience. 2015;301:254-67.

23. Boekhoudt L, Roelofs TJM, de Jong JW, de Leeuw AE, Luijendijk MCM Wolterink-Donselaar IG, et al. Does activation of midbrain dopamine neurons promote or reduce feeding? Int J Obes. 2017:41:1131-40.

24. Salamone JD, Zigmond MJ, Stricker EM. Characterization of the impaired feeding behavior in rats given haloperidol or dopamine-depleting brain lesions. Neuroscience. 1990;39:17-24.

25. Tombaugh TN, Tombaugh J, Anisman H. Effects of dopamine receptor blockade on alimentary behaviors: home cage food consumption, magazine 
training, operant acquisition, and performance. Psychopharmacology. 1979;66:219-25.

26. Wellman PJ, Davis KW, Clifford PS, Rothman RB, Blough BE. Changes in feeding and locomotion induced by amphetamine analogs in rats. Drug Alcohol Depend. 2009;100:234-9.

27. Ahlskog JE, Hoebel BG. Overeating and obesity from damage to a noradrenergic system in the brain. Science. 1973;182:166-9.

28. Palmiter RDI. Dopamine a physiologically relevant mediator of feeding behavior? Trends Neurosci. 2007;30:375-81.

29. Hnasko TS, Perez FA, Scouras AD, Stoll EA, Gale SD, Luquet S, et al. Cre recombinase-mediated restoration of nigrostriatal dopamine in dopaminedeficient mice reverses hypophagia and bradykinesia. Proc Natl Acad Sci U S A. 2006;103:8858-63.

30. Soykan I, Sarosiek I, Shifflett J, Wooten GF, McCallum RW. Effect of chronic oral domperidone therapy on gastrointestinal symptoms and gastric emptying in patients with Parkinson's disease. Mov Disord. 1997;12:952-7.

31. Warnecke T, Suttrup I, Schroder JB, Osada N, Oelenberg S, Hamacher C, et al. Levodopa responsiveness of dysphagia in advanced Parkinson's disease and reliability testing of the FEES-Levodopa-test. Parkinsonism Relat Disord. 2016;28:100-6.

32. Jicha GA, Salamone JD. Vacuous jaw movements and feeding deficits in rats with ventrolateral striatal dopamine depletion: possible relation to parkinsonian symptoms. J Neurosci. 1991;11:3822-9.

33. Rohte O. Studies of the influence of some psychotropic substances on the grooming behaviour of white mice. Psychopharmacologia. 1969;14:18-22.

34. Fornaguera J, Huston JP, Carey RJ, Schwarting RK. Stimulation of $D_{1^{-}}$or $D_{2^{-}}$ receptors in drug-naive rats with different degrees of unilateral nigro-striatal dopamine lesions. Psychopharmacology. 1995;1 19:145-54.

35. Chandler CJ, Starr BS, Starr MS. Differential behavioural interactions between the dopamine D-1 antagonist SCH 23390 and the dopamine D-2 antagonists metoclopramide and sulpiride in nonhabituated mice. Pharmacol Biochem Behav. 1990;35:285-9

\section{Submit your next manuscript to BioMed Central and we will help you at every step:}

- We accept pre-submission inquiries

- Our selector tool helps you to find the most relevant journal

- We provide round the clock customer support

- Convenient online submission

- Thorough peer review

- Inclusion in PubMed and all major indexing services

- Maximum visibility for your research

Submit your manuscript at www.biomedcentral.com/submit

) Biomed Central 